\title{
A Survey of CAARMS12 Participants
}

\author{
William A. Massey, Derrick Raphael, and Erica Walker
}

\begin{abstract}
This article describes an exploratory study of the formative, school, and professional mathematics experiences of African American participants attending the twelfth Conference for African American Researchers in the Mathematical Sciences (CAARMS12). We report information about participants' parental background, secondary school experiences, participation in mathematics-based extracurricular activities, and college and graduate school awards in the mathematical sciences. While we do not claim these results to be representative of the experiences of all African Americans in the mathematical sciences, we believe that these preliminary findings are illuminating and provide directions for future research.
\end{abstract}

\section{Introduction}

Much of the research about African Americans in mathematics describes their under-performance in school mathematics. However, much can be learned from examining the experiences of those African American students who are successful in mathematics (Walker [W6], 2006). In particular, it may be useful to examine the formative, school, and professional experiences of African Americans who have successfully pursued undergraduate and graduate degrees in mathematics (Walker [W8], 2008), as there is evidence that compared to students from other ethnicities, they are less likely to persist in these programs (Herzig [He], 2004). While there are a number of college programs (for example, Treisman's Berkeley Calculus Workshops and the Meyerhoff Scholars Program at the University of Maryland, Baltimore County) that have been effective at improving outcomes in science, technology, engineering, and mathematics (STEM) fields for African Americans, there are also a substantial number of African American scholars who are successful in mathematics without participating in such programs. What experiences do successful African American scholars in the mathematical sciences report as formative to their pursuit of graduate degrees in the mathematical sciences and their professional development?

Here we report findings from an exploratory study. This is a survey of 45 attendees of the 12th Conference for African American Researchers in the Mathematical Sciences (CAARMS12), roughly half of the total number of conference attendees. There were 17 female and 28 male survey participants. This event was held June 20-23, 2006 at the University of North Carolina, Chapel Hill and

1991 Mathematics Subject Classification. Primary 01A80.

Key words and phrases. African-American, Diversity, Mathematicians, Survey. 
SAMSI. This conference is also discussed in Massey [M]. The mission and impact of CAARMS conferences are discussed in the closing appendix for this paper. The goal of the study was to gain insight about the family, educational, and professional backgrounds and experiences of CAARMS participants.

Although this research is based on a snapshot of the conference attendees, it helps to shed much needed light on the characteristics of African Americans who have or plan to obtain a Ph.D. in the mathematical sciences. These conference attendees were given brief questionnaires to complete. They also participated in thirty to forty-five minute interviews, which enabled the interviewers to obtain an in-depth view of the lives of conference attendees. The following sections of this paper help to describe similarities and differences among this group of participants at the conference. We do not propose that sample used for the findings from this paper necessarily exhibit the characteristics of the population sought to study through any randomization process.

\section{The survey questions and the responses.}

Below are the survey questions:

(1) Where were attendees born and raised?

(2) How did individuals identify themselves?

(3) Where were participants' parents born and raised?

(4) What jobs did your parents have?

(5) What type of high schools did attendees go to?

(6) What high school interests did participants have?

(7) Participant involvement in various high school programs?

(8) What type of colleges did attendees go to?

(9) What were participants' undergraduate majors?

(10) What awards did participants win for college and graduate work?

(11) Which degrees did participants already have?

(12) Where will participants pursue a Ph.D.?

The following subsections discuss the responses to each question.

2.1. Where were attendees born and raised? In addition to the high numbers of African American attendees hailing from the United States of America (about $82 \%$ ), a significant proportion of those in attendance were also directly from Africa (13\%), see Figure 1. The important note to mention about those numbers is that the gender breakdown for African American attendees was about equal, while those from Africa were skewed in the direction of primarily male attendees. These characteristics distinguishing African Americans and Africans in the mathematical sciences also exist when all the numbers of these two groups are tallied nationwide as shown in Figures 4 and 4 of the appendix.

2.2. How did individuals identify themselves? Once again the number of participants who identified as African American was higher than any other group with about $82 \%$ selecting that category, see Figure 2. It is interesting however to also see that the percentage of those born and raised in Africa dropped to $9 \%$ from $13 \%$ while the percentage for Caribbean heritage increased. Thus, it appears that respondents who were born in Africa may also have parents with Caribbean heritage. 


\section{Where were you born and raised?}

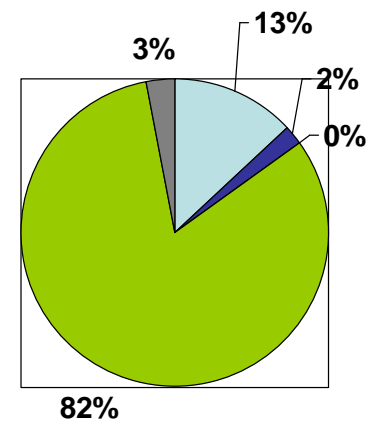

\begin{tabular}{|l|}
$\square$ Africa \\
$\square$ Carribean \\
$\square$ Europe \\
$\square$ USA \\
$\square$ Other \\
\hline
\end{tabular}

FiguRE 1. Survey question about the origins of the CAARMS12 attendees.

How do you identify yourself?

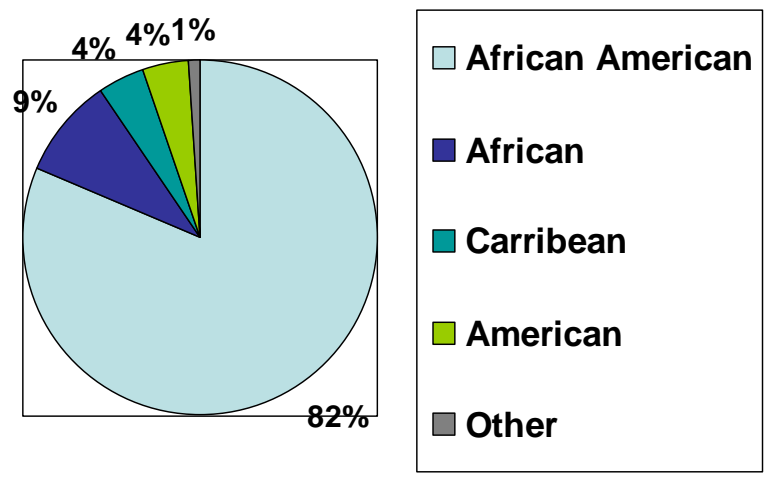

Figure 2. The self identities of the CAARMS12 attendees. 


\section{Where were your parents born and raised?}
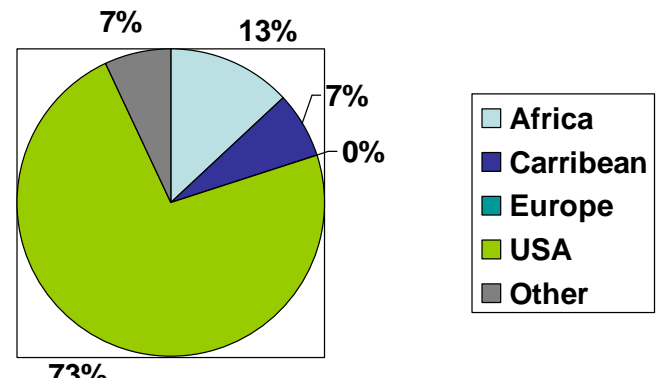

FigurE 3. The origins of the parents of the CAARMS12 attendees.

2.3. Where were participants' parents born and raised? Seventy three percent of attendees reported that their parents were born and raised in the United States, with $13 \%$ reporting that their parents were born in Africa, and $7 \%$ reporting parents who were born in the Caribbean, see Figure 3. Seven percent of the respondents also reported that their parents were from some other country. It is unclear from the data how many participants belong to households where both parents were from the same country, or two different countries. However, these results in this sections and the previous one reveal that this group of "African American" attendees is a diverse group.

2.4. What jobs did your parents have? There is one major characteristic that was brought to light through the analysis of the jobs held by the parents of conference participants. This was the relatively middle to upper middle class status held by these individuals. About $56 \%$ of participants' mothers were educators or held corporate office positions, while about $60 \%$ of the fathers of participants in the study were educators or government officials, see the graphs in Figure 4 . These high numbers of well educated and relatively affluent parents help to show why these individuals sought to obtain a Ph.D.

Thus, participants' parents were well educated and middle to upper middle class. Many researchers suggest that for African American students, a key determinant of success in school and college is the presence of networks that support academic engagement. Well educated and affluent parents may have been better able to expose their children to key opportunities that supported their mathematics development. These supplementary educational activities (Gordon, Bridglall, \& 


\section{Which categories apply to your parents' jobs?}

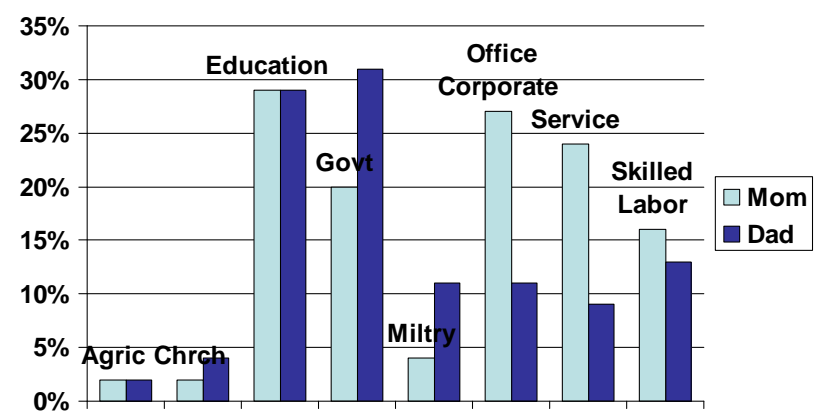

\section{Which job situation did your parents have?}

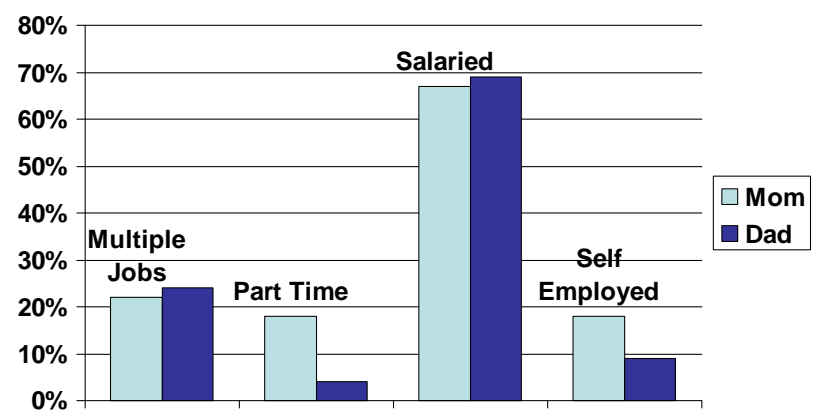

Figure 4. Survey questions about the jobs of the parents of the CAARMS12 attendees.

Meroe [G], 2005) outside of school are critical to high academic achievement for all children, but are especially critical for students from underserved groups. 


\section{What type of high school did you attend?}

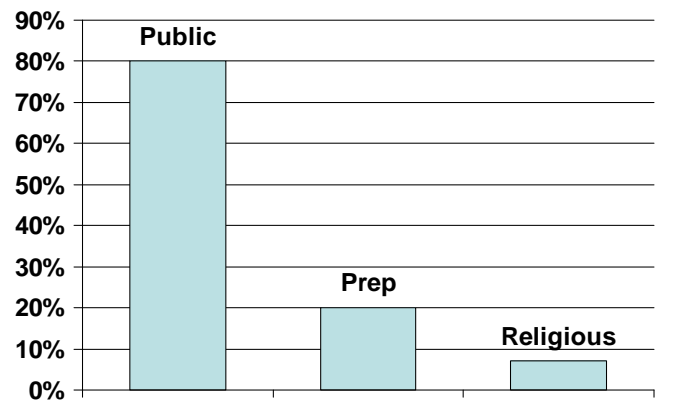

Figure 5. The type of high school that the CAARMS12 attendees went to.

2.5. What type of high schools did attendees go to? When looking over the data, it was quite revealing that most of the CAARMS participants attended public schools, see Figure 5. Of the conference attendees, $80 \%$ went to public schools. One reason for this high percentage could be due to the more nurturing environment that may have been fostered at the public schools they attended, which could have differed from a more competitive atmosphere at a private institution. Information gleaned from the in-depth interviews revealed that attending private school instead of a public one may not be in the best interest for everyone, as one individual recounted the increased academic hardship encountered at such schools. This participant, while at public school, had a perfect academic record which was lowered substantially when making the transition to private school. Now $7 \%$ of attendees attended a religious school, which may have been either a public or private school. These institutions had an important impact on the attendees as these institutions impart a particular emphasis on organization and discipline that may not have been fostered as heavily at a purely public or private school. Overall the schools that individuals attended left an important imprint on their lives and future developments.

2.6. What high school interests did participants have? Surprisingly the most popular activity for the conference attendees was not involvement in math or science based activities but sports, see Figure 6 . Over $60 \%$ of the participants were involved in some sports activity. The second most popular activity was the National Honor Society $(52 \%)$ which shows the importance of early identification for academic excellence. Third was a math/science based club (47\%). The fourth most 


\section{What were your high school interests?}

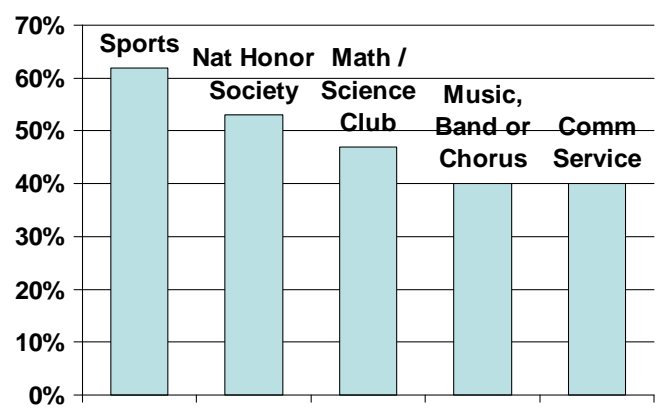

Figure 6. The type of extra-curriculum interests that the CAARMS12 attendees had in high school.

popular high school activity was a tie between (music, band or chorus) and community service at $40 \%$ showing a connection between achieving personal excellence and giving back to others.

2.7. Participant involvement in various high school programs. Many conference participants showed an early interest in math or science based groups in high school, see Figure 7 . However, only about $38 \%$ actually participated in a math-based summer program. Moreover, a mere $24 \%$ took part in an SAT prep program. This may be showing the relative strength of these individuals academically. Furthermore, they may not need the advantages to be garnered through participation in such activities. In addition, it may also be that students were not aware of math or science programs in high school, or that they chose not to participate. Further study of these issues would illuminate reasons for participation or lack there of in such programs.

2.8. What type of colleges did attendees go to? The most popular university system for the participants at the conference were historically Black colleges and universities (HBCUs), see Figure 8 . There were $42 \%$ hailing from such institutions, while $29 \%$ were from predominantly white private institutions and $29 \%$ were from predominantly white state institutions. These trends are quite surprising in some regards as the majority of black youth no longer attend HBCUs but predominantly white state institutions. One possible reason for the high numbers of Ph.D. students coming from HBCUs could be from the nurturing that may take place at an $\mathrm{HBCU}$ that may not occur at a predominantly white state or private institution. 


\section{What was your involvement in the following high school programs?}

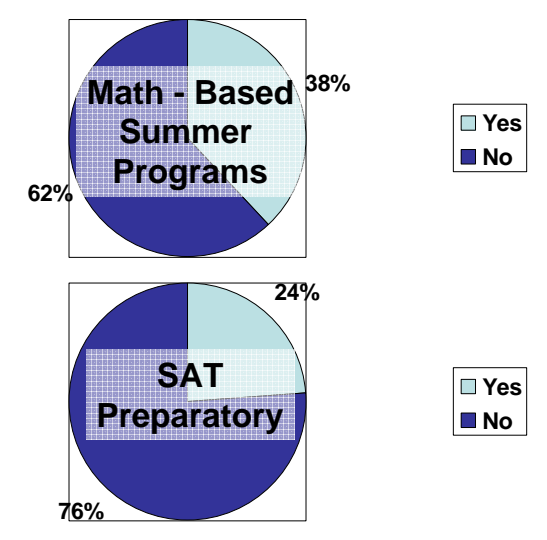

Figure 7 . The type of involvement that the CAARMS12 attendees had in math or science based summer programs in high school.

Several researchers (e.g. Hilliard [Hi], 2003; Southern Education Foundation, 2005) have found that HBCUs have specific characteristics that explain their success in steering Black students through the science, technology, engineering, and mathematics (STEM) pipeline. They provide opportunities for students to excel, facilitate peer groups that support mathematics engagement, express high expectations for the success of black students, and provide intervention for students, when needed, early and often. In many ways, effective college programs for increasing STEM participation by students of color at predominantly white institutions have replicated the best practices of HBCUs.

2.9. What were participant's undergraduate majors? Sixty six percent of conference attendees majored in a mathematical science. Engineering as a major was a distant second, with $16 \%$. Attendees also reported majors in science (9\%) and "other" majors (9\%), see Figure 9.

2.10. What awards did participants win for college and graduate work? This study showed the great importance of industrial and government sponsored scholarships for blacks seeking a Ph.D. in the mathematical sciences, see Figure 10 . With $16 \%$ of participants having their undergraduate education partially funded by industrial college scholarship and $17 \%$ obtaining industrial graduate fellowships, the importance of such funding is evident. These monies are even more vital with the current rising costs of higher education compared to their expenses in earlier times. With $22 \%$ of attendees obtaining government college scholarships 


\section{What type of college did you attend?}

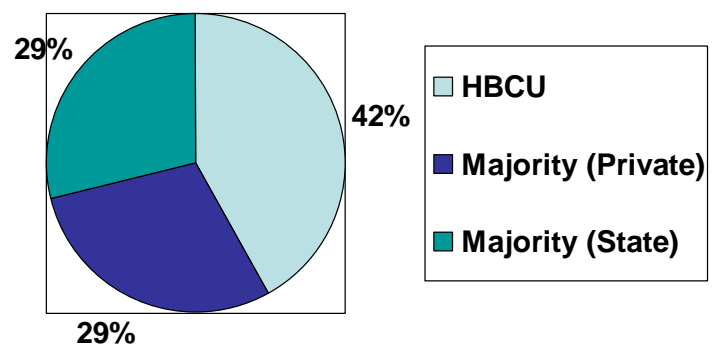

FiguRE 8. Survey questions about the type of extra-curriculum interests that the CAARMS12 attendees had in high school.

\section{What was your undergraduate major?}

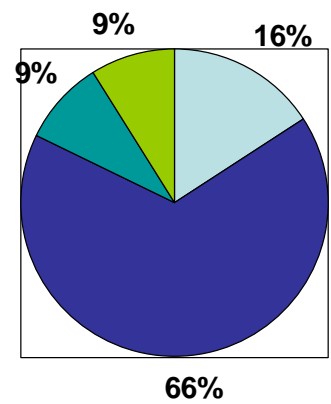

\begin{tabular}{|l|}
$\square$ Engineering \\
$\square$ Mathematics \\
$\square$ Science \\
$\square$ Other \\
\hline
\end{tabular}

Figure 9. The college undergraduate majors of the CAARMS12 attendees. 


\section{Did you win one of the following awards?}
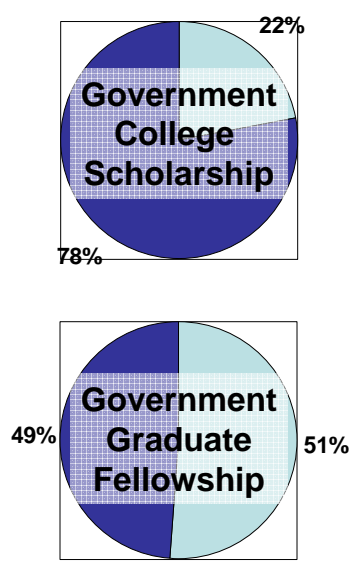
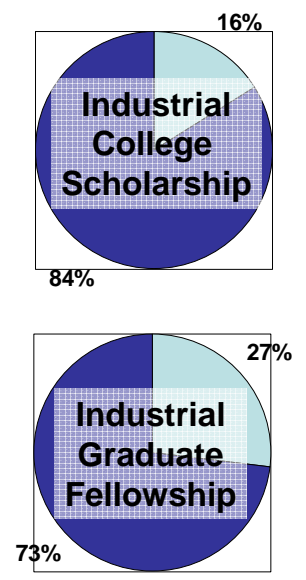

$\square$ Yes

$\square$ No

FiguRE 10. Survey question about college scholarships awarded to the CAARMS12 attendees.

and $51 \%$ winning government graduate fellowships, government support was responsible for almost half the attendees at the conference. There have been recent cut backs in government spending on initiatives to help support blacks in higher education. This could have a negative impact on the black pipeline to the Ph.D. in mathematical fields unless funding for programs is restored in the near future.

2.11. Which degrees did participants already have? About $70 \%$ of participants to the conference had degrees in the mathematical sciences, see Figure 11. This is not surprising when considering that the conference was one based on these subjects. There were also significant numbers of participants who had engineering degrees $(16 \%)$ as well.

2.12. In what fields do participants plan to pursue a Ph.D.? About $42 \%$ of participants will seek a Ph.D. in Pure Math while $23 \%$ will pursue one in Applied Math and 11\% will strive for one in Operations Research (OR), see Figure 12. The numbers obtained from these three categories make up the overwhelming majority of those participants seeking a Ph.D. in the mathematical sciences at the conference.

\section{Conclusion}

This conference obtained survey data on half of the CAARMS12 participants who had obtained or were seeking a Ph.D. in the mathematical sciences. Our analysis showed that many individuals came from solidly middle or upper-middle class backgrounds but not exclusively. One notable characteristic that was garnered 
Which degrees do you have now?

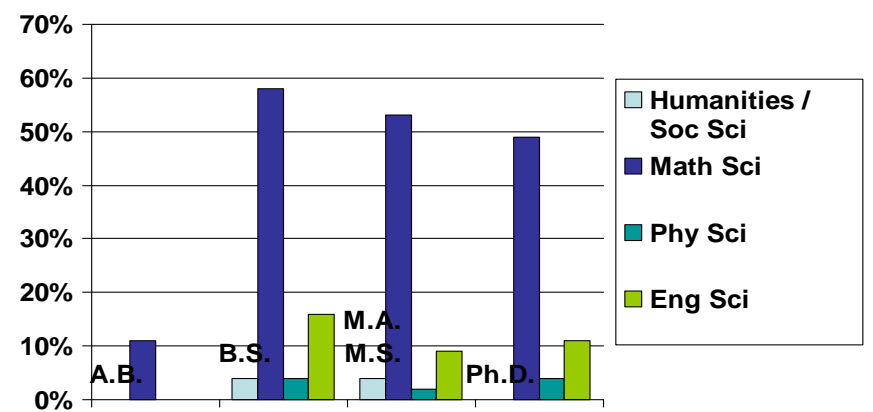

Figure 11. The undergraduate and graduate degrees that the CAARMS12 attendees currently have.

\section{Where have, are, or will you pursue a Ph.D.?}

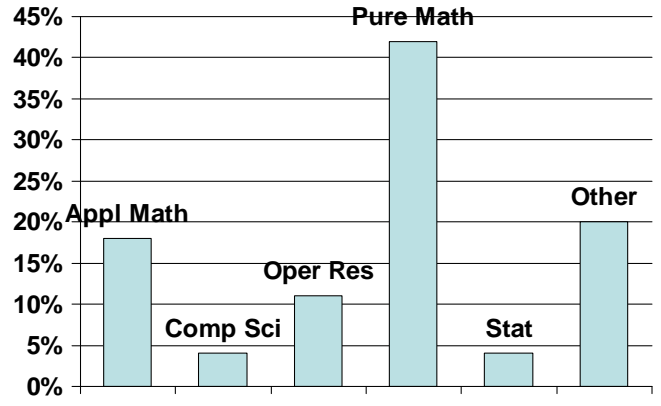

Figure 12. The technical fields for which the CAARMS12 attendees plan to (or already have) pursue a Ph.D. 
through the in-depth interviews were the high numbers of participants coming from two-parent households. Other factors seem to arise in these surveys that give a sense of what it takes to obtain a Ph.D. Factors such as a supportive family structure and significant involvement in extracurricular activities in high school such as sports, music or math/science based clubs.

This exploratory study, even with its limitations, has revealed several potential avenues for further examination. First, more information should be gathered about the kinds of supplementary educational activities and formative childhood experiences that African American Ph.D. holders and candidates in the mathematical sciences have as children and adolescents. Second, additional probing should be done about the kinds of extracurricular activities that were available to students, and how other out of school activities-perhaps structured by parents-helped to augment school experiences of the respondents. Finally, given that similar numbers of African American male and female students are successful in gaining the Ph.D., while for other groups-including Africans-the results are skewed toward males, further study of the dynamics that contribute to this parity should be explored.

\section{References}

[G] Gordon, E.W., Bridglall, B.L., and Meroe, A.S. (2005). Supplementary education: The hidden curriculum of high academic achievement. Lanham, MD: Rowman and Littlefield.

[He] Herzig, A.H. (2004). Becoming mathematicians: Women and students of color choosing and leaving doctoral mathematics. Review of Educational Research, 74 (2), 171-214.

[Hi] Hilliard, A. (1995). The maroon within us. Baltimore, MD:Black Classic Press.

[K] Kenschaft, P.C. (2005). Change is possible: Stories of women and minorities in mathematics. Providence, RI: American Mathematical Society.

[M] Massey, W. A. (2001). Mathematics is Four Dimensional. Council for African American Researchers in the Mathematical Sciences: Volume III. Contemporary Mathematics, editors Alfred Noel, Earl Barnes and Sonya A. F. Stephens. Volume 275, pp. 147-158.

[S] Southern Education Foundation (2005). Igniting potential: Historically black colleges and universities and science, technology, engineering, and mathematics. Atlanta, GA: Author.

[W6] Walker, E.N. (2006). Urban high school students' academic communities and their effects on mathematics success. American Educational Research Journal, 43 (1), 41-71.

[W8] Walker, E.N. (2008). Mathematical (role) models: How Black mathematicians mentor, teach, and practice. Paper presentation at the Annual Meeting of the American Educational Research Association, New York City, NY.

\section{Appendix}

The Conference for African American Researchers in the Mathematical Sciences (CAARMS) came into existence in 1995 to encourage, nurture, and promote African American researchers in the mathematical sciences, current and potential. We define the mathematical sciences in the broadest sense to include pure and applied mathematics, operations research, statistics, computer science and other technical fields where mathematics plays a major role. The conference also exists to complement and cooperate with other established groups that promote AfricanAmericans in the mathematical sciences.

The conference is primarily (but not exclusively) aimed at showcasing the research of African-Americans mathematicians. At the same time we have invited noted Hispanic mathematicians to speak at CAARMS such as Richard Tapia or Rice University, Rodrigo Bauelos of Purdue University and Carlos Castillo-Chavez of Arizona State University as well as Native American mathematicians such as Robert Megginson of the University of Michigan. 
We have also invited mathematicians from the majority community to speak at CAARMS such as Steven Shreve of Carnegie Mellon University, Jerry King of Lehigh University, Robert Vanderbei of Princeton University, Margaret Wright of New York University, Ward Whitt of Columbia University, and Christopher Jones of the University of North Carolina at Chapel Hill and SAMSI. We have also invited speakers from the international community such as Carl Graham from the École Polytechnique in Paris.

The format of the conference is to have 10 researchers each give hour long talks about their research. Additional lectures may be given of an expository nature like a tutorial. At the end of each day, we have complementary events such as on Wednesday there is a graduate student poster session. on Thursday there is a conference banquet and a keynote speaker. Finally, on Friday we have a closing group discussion about careers in the mathematical sciences or future goals for CAARMS. One key feature of our conferences is that we do not have any parallel sessions. This encourages everyone to attend all the lectures and get exposed to different aspects of research in the mathematical sciences.

The conferences have been successful in attracting some of the best African American mathematical sciences graduate students in the country to CAARMS conferences. Since 1996, we have consistently had 20 graduate students participate each year for the CAARMS poster sessions. Over 70 African American graduate students from the previous CAARMS meetings have since gone on to receive a Ph.D. in the mathematical sciences. Their names are listed below. We have also had over 13 conference participants go on to become tenured university professors in the mathematical sciences.

Here is the list of past graduate student CAARMS attendees, who later obtained Ph.D.'s in the mathematical sciences, along with the university that offered the degree. The code for the field of their degree is Math=mathematics, Stat=statistics, $\mathrm{OR}=$ operations research or industrial engineering, $\mathrm{CS}=$ computer science, $\mathrm{EE}=$ electrical engineering, and Chem=chemistry.

(1) Kobi Abayomi - Columbia University (Stat)

(2) Gerard Anawou - University of Georgia (Math)

(3) Jamika Burge - Virginia Polytechnic Institute \& State University (CS)

(4) Sean Brooks - Howard University (Math)

(5) Naiomi T. Cameron - Howard University (Math)

(6) Garikai Campbell - Rutgers University (Math)

(7) Jamylle Laurice Carter - University of California at Los Angeles (Math)

(8) William Christian - Rice University (OR)

(9) Jimmie Lee Davis Jr. - University of Massachusetts at Lowell (EE)

(10) James DeBardelaben - Georgia Institute of Technology (EE)

(11) Jules Degilia - Ecole Polytechnique de Montreal (EE)

(12) Gelonia L. Dent - Brown University (Math)

(13) Shurron Farmer - Howard University (Math)

(14) Jonathan David Farley - Oxford University (Math)

(15) Jeffery Forbes - University of California at Berkeley (CS)

(16) Jeffery Fleming - Howard University (Math)

(17) Musie Syum Gheremichael - Rice University (Stat)

(18) Juan Gilbert - University of Cincinnati (CS)

(19) Nancy Glenn - Rice University (Stat) 


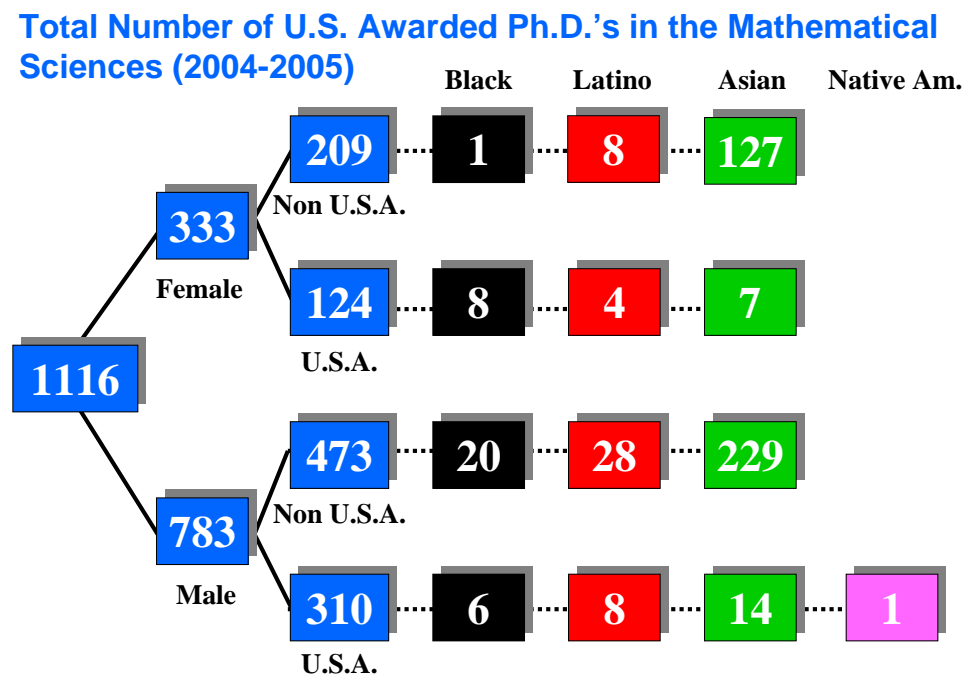

Data from AMS Notices, February 2006

Figure 13. AMS data on the citizenship, ethnic, and gender breakdown of mathematics Ph.D.'s awarded in the United States during 2004-2005.

(20) Edray Goins - Stanford University (Math)

(21) Russell Goward - University of Missouri at Columbia (Math)

(22) Madison Gray - University of California at Los Angeles (Math)

(23) Robert Hampshire - Princeton University (OR)

(24) Ben Hansen - University of California at Berkeley (Stat)

(25) John A. W. Harkless - University of California at Berkeley (Chem)

(26) Illya Hicks - Rice University (OR)

(27) Raquel Hill - Harvard University (CS)

(28) Rudy Horne - University of Colorado at Boulder (Math)

(29) Louise Hosseini-Nasab (formerly Louise Brown) - Georgia Institute of Technology (OR)

(30) Mave Houston - Auburn University (CS)

(31) Tasha Inniss - University of Maryland, College Park (Math)

(32) Monica Jackson - University of Maryland, College Park (Math)

(33) Jean-Michelet Jean-Michel - Brown University (Math)

(34) Byron A. Jeff - Georgia Institute of Technology (CS)

(35) Otis Jennings - Georgia Institute of Technology (OR)

(36) Michael Keeve - Georgia Institute of Technology (Math)

(37) Kathryn Lewis - Purdue University (Math)

(38) Mark Lewis - Georgia Institute of Technology

(39) James W. McGee, III - Auburn University (Math)

(40) Douglas McWilliams - North Carolina A\&T (OR) 


\section{Total Number of U.S. Awarded Black Ph.D.'s in the Mathematical Sciences (2001-2005)}

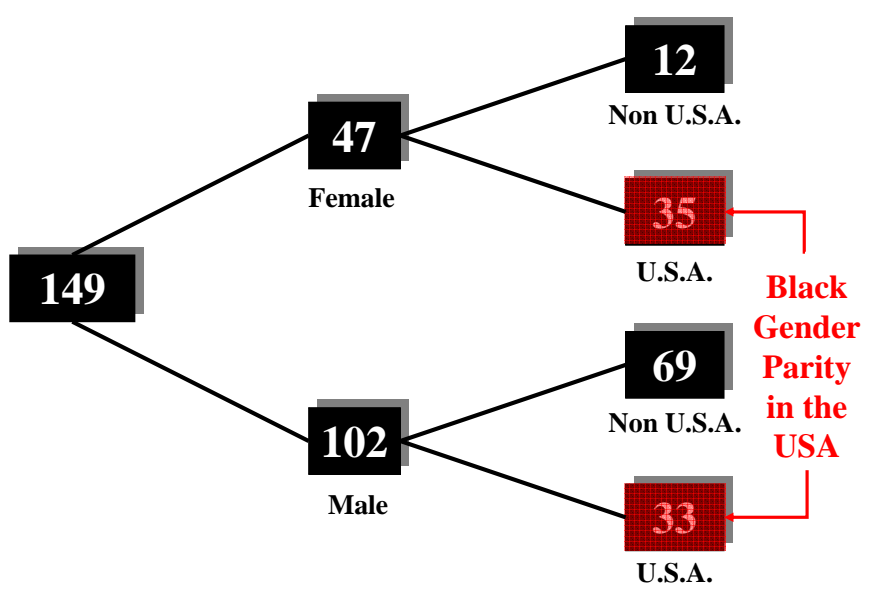

Data from AMS Notices

Figure 14. AMS data on the citizenship, ethnic, and gender breakdown of Black mathematics Ph.D.'s awarded in the United States in the 21st Century.

(41) Cassandra McZeal - Rice University (OR)

(42) Irene Moshesh - Howard University (Math)

(43) Rod Moten - Cornell University (CS)

(44) Milton Nash -University of Georgia (Math)

(45) Yared Nigussie - Ohio State University (Math)

(46) Asamoah Nkwanta - Howard University (Math)

(47) Alfred Noel - Northeastern University (Math)

(48) Kasso Okoudjou - Georgia Institute of Technology (Math)

(49) Jakita Owensby - Georgia Institute of Technology (CS)

(50) Ahmed Ridley - University of Maryland, College Park (Math)

(51) Lemmuel Riggins - Case Western Reserve University (Math)

(52) Errol Rowe - University of Maryland, College Park (Math)

(53) Sherry Scott - University of Maryland, College Park (Math)

(54) Kimberly F. Sellers - George Washington University (Stat)

(55) Rhonda Sharpe - Claremont Graduate School (Math/Econ)

(56) Charles Shelton - Carnegie Mellon University (Comp Eng)

(57) Mark Smith - Massachusetts Institute of Technology (CS)

(58) Desmond Stephens - Florida International University (Math)

(59) Idris Stovall - University of Massachusetts at Amherst (Math)

(60) Craig Sutton - University of Michigan (Math)

(61) Barbara A. Tankersley - Howard University (Math)

(62) Kendra Taylor - Georgia Institute of Technology (OR) 
(63) Simon Gikiri Thuo - University of Maryland, College Park (Math)

(64) Alain Togbe - Laval Universite (Math)

(65) Rachel Vincent - Rice University (Math)

(66) Rodney Wallace - George Washington University (OR)

(67) Kimberly Weems - University of Maryland, College Park (Math)

(68) Bryan Williams - University of Mississippi (Math)

(69) Pamela Williams - Rice University (OR)

(70) Adrian Wilson - University of Mississippi (Math)

(71) Ulrica Wilson - Emory University (Math)

(72) Aristotle Winger - Carnegie Mellon University (Math)

Department of Operations Research and Financial Engineering, Princeton UniverSity, Princeton, New Jersey 08544

E-mail address: wmassey@princeton.edu

Duke University School of Law, Durham, North Carolina 27708

E-mail address: derrick.raphael@law.duke.edu

Program in Mathematics Department of Mathematics, Science, and Technology Teachers College, Columbia University, New York, New York 10027

E-mail address: ewalker@exchange.tc.columbia.edu 